\title{
The Manager's Paradox: Differential Treatment without Favoritism
}

\author{
Robert L. Routhieaux ${ }^{1}$ \\ ${ }^{1}$ Hamline University School of Business, Saint Paul, Minnesota, USA \\ Correspondence: Robert L. Routhieaux, Hamline University School of Business, USA. E-mail: \\ rrouthieaux01@hamline.edu
}

Received: March 5, 2015

Accepted: March 24, 2015

Online Published: April 20, 2015

doi:10.5539/ijbm.v10n5p251

URL: http://dx.doi.org/10.5539/ijbm.v10n5p251

\begin{abstract}
Managers and supervisors at all levels of organizations face an ongoing interpersonal paradox. Due to individual differences and role identities, managers must adapt communication and motivation techniques according to differential employee needs and goals. But as soon as managers start to communicate and interact with employees in different ways, they run the risk that their actions will be perceived as inconsistent or unfair. This complex set of interdependent challenges, where managers have seemingly contradictory expectations regarding employee communication, treatment, and perceptions, can be referred to as the manager's paradox. This paper will outline the contextual factors that foster the manager's paradox, discuss a specific set of challenges related to the manager's paradox, and provide key strategies for navigating and balancing the manager's paradox. The goals are to shed new light on the challenges of managing people, outline suggestions for improving management effectiveness, and provide ideas for reducing the stress associated with managing people.
\end{abstract}

Keywords: human resource management, supervision, employee relations

\section{The Context of Being a Manager or Supervisor}

\subsection{Overview of Manager Position and Expectations}

Describing the work of managers and supervisors can be approached in many ways. One of the more common is to classify the different functions of being a manager. Fayol (1949) grouped these functions into five areas, planning, organizing, commanding, coordinating, and controlling. This list of functions has been widely cited and used in organizing management textbooks (Carrol \& Gillen, 1987). Within each function of this framework are a subset of tasks and activities. Most of these tasks and activities are relatively easy to learn and implement like planning for a meeting, setting up an organizational reporting chart, or controlling costs through refinement of policies and procedures. From this functional approach, the main challenge of being a manager is developing the breadth of knowledge and skills needed to be proficient in all areas.

An alternative approach to describing the work of managers and supervisors is to examine the roles that they perform. As classically outlined by Mintzberg (1971), managers play a wide variety of informational, interpersonal, and decisional roles. This wide variety of roles requires an extensive set of knowledge and skills. While many managers have the knowledge and skills to be adept at certain roles, experience and evidence suggest that most managers cannot master all of them. To further complicate matters, most managers have little time to themselves to develop the knowledge and skills needed to navigate the multiple roles. Plus, managers are often required to move from role to role so quickly that they may not have the time needed to properly address the expectations that are placed on each role.

Katz (1974, from original work dated to 1955) outlined three key skills needed to be an effective manager / administrator. These include technical skills, human skills, and conceptual skills. His insights on human skills regarding listening to and adapting to others remains insightful and applicable nearly 60 years after initially written. This and subsequent work focused on how the importance of these difference skills might vary at different levels of an organization. One such investigation (Schmidt \& Hunter, 1992) produced an interesting result. Of the four key skills of effective managers (they add motivation to manage as a fourth skill), only the human skills were rated at high importance at all levels. Thus, regardless of where a manager is positioned within an organization, their ability to navigate complex human relations is a critical factor in their success.

Peter Drucker provided numerous insights on the manager's job in Management Tasks, Responsibilities, Practices (1974). Drucker explored some of the challenges in managing people, and the difficulties in balancing 
time on the 'routine' tasks of being a manager with the pressures of being responsible for the productivity of others. Similar to Mintzberg, Drucker provided comprehensive review of the many different activities associated with being a manager, and added additional insights on how to be more effective and efficient as a manager.

Since then, a wide variety of authors have expanded on the challenges associated with being a manager. Belker \& Topchik's The First-Time Manager: A Practical Guide to the Management of People (2005) provides a notable compendium on the challenges faced by managers. Much of their focus, akin to Linda Hill's classic "Becoming the Boss" article (2007), is on the misconceptions or misperceptions new managers have about their roles, power, influence, and autonomy.

From all of these writings on being a manager or supervisor, one theme seems clear: the major challenge of being an effective manager, and often the area that managers cite as their biggest concern or frustration, is managing people. To be effective in the interpersonal aspects of the job, managers and supervisors must learn to understand, interpret, and adapt to the differential values, needs, goals, and expectations of their employees and other constituents. Managers must learn to balance competing priorities, conflicting interpersonal styles, delicate identities associated with specific roles, and the general drama that comes with any group of people. As a result, effective managers must learn to balance the need for differential communication and interaction with employees while minimizing perceptions of differential treatment / fairness. This challenge can be referred to as the manager's paradox.

\subsection{Balancing Differential Employee Needs and Expectations}

From my own experiences as a manager, management trainer, and professor of management, one of the most notable misconceptions of new managers, and even seasoned managers, is that "a good manager needs treat everyone the same." Clearly, this approach has face validity, and practical validity, on a number of fronts. Yes, everyone should be treated the same in terms of hiring practices, disciplinary procedures, and even in being able to voice their opinions and concerns. But as all seasoned managers know, treating everyone the same is fraught with limitations.

The simple way to explain the limitation of treating everyone the same is to cite the very clear and real need for managing diversity in an organization. As countless authors and practitioners have noted in recent years, people are different and need to be treated differently out of respect for unique values, backgrounds, talents, and goals (Harrison et. al, 1998). People have different styles of communication, different ways of learning, different ways of processing information and making decisions, and different ways of relating to people and the world around them. Given these differences, the manager needs to become adept at self-monitoring (Snyder, 1974), and adapt their own communication and relational patterns in dealing with others.

For example, an after-school program manager serving at risk youth will need to work with a broad range of constituents. From staff to volunteers to youth to parents, each person will bring their own perspectives and background. Each of these individuals will have their own style of communication, and their views of good communication and coordination will differ based on their preferred styles. Some will prefer a direct and matter of fact communication style. Others will work better if the program manager uses more accommodating and encouraging communication. In trying to serve and accommodate these different styles, the program manager will need to adapt by adjusting interaction and communication patterns. But, in doing so, the program manager will be challenged in not giving off perceptions of favoritism to others. In addition, the program manager will be challenged in feeling like their interaction and communication patterns are authentic.

This need for differential treatment, and the complications in doing so, can be further explored through the lenses of role theory.

\section{Inherent Role Conflict of Manager Position}

The manager's job is inevitably complex because there is inherent role conflict in being a manager. The inherent role conflicts of being a manager stem from a variety of sources. These sources, and the following discussions, can be examined using Katz \& Kahn's review of role theory, from Social Psychology in Organizations (1978).

The first source of inherent role conflict in being a manager is the multitude of role senders, who have very different and often conflicting role expectations. Role senders are any persons with whom a manager comes in contact, and each will have their unique expectations of the manager. Inter-role conflict stems from the differential set of roles senders that the manager must interact with. In essence, managers can be viewed as in the middle of a wide variety of role senders. Much like stakeholder analysis, managers can be viewed as the hub of a very complex wheel of relationships. On any given day, and often within a very short time frame in a given day, managers may have to interact with subordinates, superiors, other managers at similar levels with the 
organization, clients, funders, vendors, and others (Mintzberg, 2009). In doing so, they must quickly adapt their communication styles in consideration of the needs, goals, and priorities of the parties with whom they interact.

Different role senders often send conflicting expectations of the manager. While each may want their share of the manager's time, they also expect their needs to be listened to and addressed. The manager's boss may send expectations that the manager attend more meetings with the management team, and continue to reduce costs in operations. The manager's subordinates are likely to send expectations that the manager spend more time providing them feedback and support, while continuing to increase resources available to them (including pay). Other managers may want to share challenges with certain divisions, and request political and human resource support for new initiatives. Clients, funders and vendors may expect certain accommodations or information that exceeds the manager's authority or conflicts with the expectations and needs of superiors and subordinates.

In addition, and more to the focus of this paper, managers also must deal with intra-role conflict - conflict derived from differential expectations regarding one particular role. For managers, this plays out in terms of different expectations of subordinates. It can also play out based on different expectations by superiors or peers or other role sets. One employee may prefer a manager that is primarily task focused, who provides clear and concise guidelines for work to be accomplished with little or no extraneous discussion. A second employee may prefer a manager that is more relationship focused, who will engage in both professional and personal discussions and provide emotional support during difficult times. A third employee may be a top producer, but expect extra accommodations for a complicated personal life (caring for a sick child or parent). Clearly, the 'good' manager will need to balance these competing expectations.

Further complicating the sources of inter-role and intra-role conflict are the role identities and associated goals and priorities of the different role senders. As suggested in social identity theory (Tajfel \& Turner, 1986), people derive meaning and importance from the roles they adopt and the groups with which they affiliate. The roles people adopt and the work they do become part of their persona, and the manager must understand that all role senders have an additional layer of ego dynamics associated with their position. Thus, in trying to understand and balance inter-role and intra-role conflicts, managers must be aware of additional sensitivities.

These sensitivities play out in perceptions of fairness. What is clear from sociological and organizational research is that all people want to feel respected and treated fairly. These perceptions of fairness can be classified as perceptions of equity, and an individual's emphasis on the importance of fairness has been labeled equity sensitivity (Huseman, Hatfield, \& Miles, 1987). Perceptions of inconsistency and unfairness foster notions of favoritism, and can lead to negative organizational politics. These, in turn, complicate the manager's efforts to build and maintain a productive and collaborative workforce.

\subsection{Short-Term Expectations versus Long-Term Success}

For most successful managers and supervisors, navigating the differential expectations that lead to the manager's paradox requires long term orientation. Focus on short term conflicts, individual feelings of favoritism, and daily needs for attention can detract from a manager's goal to build a collaborative and healthy work environment for staff and colleagues. Managers must recognize that nearly all individuals will at times feel somewhat slighted or treated unfairly. While it is important to recognize and sometimes address these instances as they arise, navigating the manager's paradox requires a more holistic and long term approach.

A long term approach to managing interpersonal relationships has many components, but in connection to the manager's paradox there appear to be three key strategies. First, and most important, is open dialogue between the manager and his/her staff regarding the interpersonal challenges associated with the position. Second, managers must develop the ability to separate individual conflicts and complaints from overall culture and climate. Third, managers need to learn to not internalize the frustrations of others while maintaining sincere concern for others and their well being.

For many new managers, particularly within certain cultures and sub-cultures, admitting their challenges and frustrations with the staff they manage seems counter-intuitive. The desire to be respected as an authority figure can inhibit managers from exposing openly their own uncertainties associated with their job. However, only through open dialogue with direct reports can managers hope to develop a staff that empathizes with the joys, challenges, and frustrations of being the manager.

Since many of a manager's direct reports may not have served in similar manager positions, the only way to get staff to understand the manager's complex set of role requirements is through open dialogue. These conversations are critical in navigating the manager's paradox. Openly addressing perceptions of favoritism requires an ability to deal with conflict in direct but non-confrontational means (Patterson et al., 2002). Managers 
and supervisors must create a culture of ongoing dialogue and demonstrate a willingness to engage in uncomfortable conversations.

In establishing this culture of ongoing dialogue, managers need to understand that concerns and conflicts will naturally emerge. Individual complaints or frustrations must be seen as such, and managers cannot let isolated incidents overly shadow overall purpose and direction. This can be a challenge, particularly when a manager feels like they jump from incident to incident with little time to reflect on the past and plan for the future. Keeping the big picture in focus when lots of little details and issues need to be continually addressed can be difficult. However, if an overall culture of open dialogue and future focus can be developed, working past individual instances of staff dissatisfaction will not be overly time consuming or stress inducing.

Stress is an unavoidable byproduct of being a manager. Balancing ongoing demands for results with ongoing interpersonal challenges and role conflicts creates an inherently stressful context. This contextual stress can be overwhelming unless a manager can learn to not take things personally when people are unhappy or frustrated. Managers must have sincere concern and empathy for their staff, but if they overly internalize the negative perceptions and feelings of their staff they subject themselves to unnecessary and often destructive stress.

In developing a long term approach and perspective on managing, managers and supervisors must recognize that balance is critical. In managing people, there is rarely a "right way" of doing things. Instead, managers must learn to balance their approaches based on the unique circumstances and individuals. Of course, doing things differently at different times and with different people harkens back to the fundamental source of the manager's paradox. The key is, over the long term, to balance different approaches in a way that the manager can communicate to staff-and that staff can understand. There is no end-game in dealing with the manager's paradox. It is an evolving and dynamic set of processes that is best approached as a joyful game of balance. Understanding the dimensions of this game of balance is critical to ensuring the manager's long term success in building a collaborative, positive and productive work force.

\section{The Balancing Act in Dealing with the Manager's Paradox}

As discussed above, navigating the manager's paradox requires balance. This notion of balance can be applied to many dimensions of managing people. Below, some of these dimensions are discussed and illustrated. This list is not intended to be exhaustive or complete. It is intended as a starting point for managers to consider in developing a thoughtful approach to the many dimensions of the manager's paradox.

\subsection{Need for Directive and Democratic Decision Making}

Managers are decision makers. By very definition, managers are put in place to get things done through utilization of human and other resources. Their power initially stems from their authority to make decisions. However, managers that try to make all the decisions that need to be made by themselves soon become overwhelmed, and staff become detached and less supportive. Good managers understand that there is clear need to balance different decision styles. From autocratic to consultative to completely delegated decision making, no one approach works in all circumstances (Hersey, Blanchard \& Natemeyer, 1979). Managers and supervisors must recognize that at times they are expected to and need to make decisions on their own. In other circumstances, getting input from others or delegating decisions is the best approach. And, regardless of the decision made, different employees will evaluate and judge decisions differently based on personal expectations, beliefs, and roles.

\subsection{Need for Task and Relationship Focus}

As discussed above, some employees are primarily task focused, while others adopt more relationship focus at work. Managers must find a happy medium and learn to work with differential employee orientations. This can be a challenge, since most managers will also have their preferred style which may skew towards task or relationship focus. One approach that can help in this balance is adopting an interdependency perspective. Instead of viewing task and relationship focus as two ends of a continuum, they can be perceived from a yin-yang perspective-mutually important and enhancing perspectives that are not complete without the other. Positive relationships help to ensure dedication to tasks, while task orientation helps provide a catalyst on which to build positive relationships.

\subsection{Need for Respect and Desire for Being Liked}

In balancing dedication to task completion with positive relationships, managers will need to confront the importance of both respect and liking. Managers can be respected for their dedication and knowledge without being particularly liked by their employees. Similarly, employees might like a manager personally but not respect their capabilities as a manager or supervisor. Clearly the ideal is to be both respected and liked, but this 
can be particularly difficult when managers need to make difficult decisions. As with task and relationship focus, this balance may best be viewed as mutually enhancing perspectives. Respect will often come from employees who feel they are treated fairly, and who perceive their manager as competent in the tasks of being the manager. Liking will be facilitated by fair treatment, and greatly enhanced through strong attention to relationships. As alluded to above, this balance must be viewed from a long-term, holistic approach. Managers and supervisors have to accept that at times they will need to make decisions that other may not agree with, and this may put temporary strain on relationships.

\subsection{Need for Expertise and Humility}

Managers are generally hired based on their proven expertise in knowledge or skills associated with the job and organization. This can lead some managers to develop heightened sense of self-worth, where they feel the need to be involved in or control all major decisions. It can also create an aversion to admitting weaknesses or exposing vulnerabilities. However, managers who are gifted at balancing the demands of the position understand that a strong dose of humility is essential. As discussed above, good managers can admit mistakes (and learn from them), involve employees in decisions, and openly discuss their own hesitations and frustrations. Doing so must be done selectively and intentionally. Managers need to provide direction and expertise on a regular basis to maintain respect and strong task orientation. But they must also be willing to at times confess to lack of knowledge or expertise in certain circumstances.

\subsection{Need to Treat People Differently and Maintain Consistency}

This balance is the crux of the manager's paradox, and encompasses all of the areas of balance discussed above. Approaching each situation and individual with an open mind and adaptive intent can be difficult, particularly when a manager feels "I have dealt with this successfully in the past, so I know how to approach the same thing here." Of course, in certain cases managers must demonstrate unwavering consistency of action. There should be clear equity in terms of respect shown to others, administration of disciplinary procedures, employment decisions, and dealing with legal or risk-related issues. In other situations, such as declining performance, troubles in personal lives, interpersonal conflicts, or work-life balance concerns, unique approaches will be most effective. The key, and the real challenge, is for managers to approach such instances with a carefully developed thought process driven by long-term intentions.

\section{Conclusion}

The growing inter-generational and cross-cultural dynamics of work environments in many locations creates new challenges for managers and supervisors. The emerging necessity for proactive and authentic approaches to managing diverse staff and volunteers heightens the need for adaptation and customization. However, in adapting to individual needs and customizing communication patterns, managers and supervisors must be cautious in mitigating perceptions of favoritism. The ability to navigate this manager's paradox will be critical in the overall effectiveness of any manager or supervisor. This article was intended to provide guidance on gracefully dealing with the manager's paradox.

Readers should note that there is no magic potion for navigating the manager's paradox. The ongoing human dynamics within the world of work creates a tapestry of colorful interactions. The managers and supervisors that learn to tap into their artistic mindset in dealing with the never ending rippling waters of working with people will fare best. Through thoughtful reflection, ongoing and open dialogue, and a sense of humility and playfulness, managers and supervisors can learn to joyfully ride the waves of the manager's paradox.

\subsection{Strategies for Navigation and Balance-Implications for Practice}

So, what can managers and supervisors do to navigate the manager's paradox? This section outlines some key strategies for creating a balanced approach to the challenges of managing people. These suggestions are presented as short lists of ideas focused on three levels of intended audience for this article - managers, organizations, and education providers. Each has a unique and complementary role in helping ensure the success of managers in navigating the manager's paradox.

\subsection{What Managers and Supervisors can Do to Navigate the Manager's Paradox}

Be open in admitting and discussing the challenges of being a manager with your employees. Be explicit in discussing the challenges of providing individualized treatment and attention without fostering perceptions of favoritism.

Develop a strong support network, at work and in other domains. Seek out other managers with whom you can share your joys, frustrations and ideas. 
Learn to control your ego influences. Learning to not take things personally and acknowledging your limitations is an ongoing process. Study different approaches and philosophies for doing so.

Integrate a wide variety of stress management techniques into your daily and weekly routines. Take time to refresh yourself at some point during each day, and for at least a few hours each week.

\subsection{What Organizations can Do to Help Managers Navigate the Manager's Paradox}

Acknowledge and address manager challenges. Provide resources for managers for ongoing personal and professional development. Help connect them with supportive organizations and groups.

Prepare new managers for the challenges they will face. Have experienced and respected managers from within the organization and from other organizations provide training and mentoring for new managers.

Build timelines and schedules that allow for quiet reflective time for managers. Encourage managers do build personal development and stress management plans into their annual goals.

Provide employees with training and dialogue on working with your manager. Openly share with non-managers the roles and challenges of being a manager.

\subsection{What Education Providers can Do to Prepare Managers for the Manager's Paradox}

Focus less on leadership, more on management. While study of leadership is good, more emphasis on the tasks and challenges of being a successful manager is needed to prepare future managers (see Mintzberg, 2004, for a compelling discussion on this point).

Be realistic, not idealistic. Presenting ideals and extensive review of theories can be beneficial, but more practical approaches to manager development will provide better grounding and training for current or future managers.

Supplement management textbooks with a wide variety of readings. Incorporate popular press books not just from the business literature, but also other sources. Include readings from philosophy, psychology, sociology, and the arts to help develop more holistic and long term approaches.

Encourage mentoring programs and internships. Provide students with realistic job previews of being a manager by putting them in management positions - and supporting them through the journey.

\section{References}

Belker, L. B., \& Topchik, G. S. (2005). The First-time Manager (5th ed.). New York, NY: AMACOM.

Carroll, S. J., \& Gillen, D. J. (1987). Are the Classical Management Functions Useful in Describing Managerial Work? The Academy of Management Review, 12(1), 38-51. http://dx.doi.org/10.5465/AMR.1987.4306460

Drucker, P. F. (1974). Management: Tasks, Responsibilities, Practices. New York: Harper \& Row.

Fayol, H. (1949). General and Industrial Management. Pitman.

Harrison, D. A., Price, K. H., \& Bell, M. P. (1998). Beyond relational demography: Time and the effects of surface-and deep-level diversity on work group cohesion. The Academy of Management Journal, 41(1), 96-107. http://dx.doi.org/10.2307/256901

Hersey, P., Blanchard, K. H., \& Natemeyer, W. E. (1979). Situational Leadership, Perception, and the Impact of Power. Group Organization Management, 4(4), 418-428. http://dx.doi.org/10.1177/105960117900400404

Hill, L. A. (2007). Becoming the Boss. Harvard Business Review, 85(1), 48-56.

Huseman, R. C., Hatfield, J. D., \& Miles, E. W. (1987). A New Perspective on Equity Theory: The Equity Sensitivity Construct. The Academy of Management Review, 12(2), 222-234. http://dx.doi.org/10.2307/258531

Katz, D., \& Kahn, R. L. (1978). The social psychology of organizations (2nd ed.). New York: Wiley.

Katz, R. L. (1974). Skills of an Effective Administrator. Harvard Business Review, 52(5), 90-102.

Katz, R. L. (1974). Skills of an effective administrator. Boston: Harvard Business Review.

Mintzberg, H. (1971). Managerial Work: Analysis from Observation. Management Science, 18(2), 97-110. http://dx.doi.org/10.1287/mnsc.18.2.B97

Mintzberg, H. (2004). Managers, not MBAs: A hard look at the soft practice of managing and management development. San Francisco, CA: Berrett-Koehler.

Mintzberg, H. (2009). Managing. San Francisco: Berrett-Koehler Publishers. 
Patterson, K. (2002). Crucial conversations: Tools for talking when stakes are high. New York: McGraw-Hill.

Schmidt, F. L., \& Hunter, J. E. (1992). Causal modeling of processes determining job performance. Current Directions in Psychological Science, 1, 89-92. http://dx.doi.org/10.1111/1467-8721.ep10768758

Snyder, M. (1974). Self-monitoring of expressive behavior. Journal of Personality and Social Psychology, 30 , 526-537. http://dx.doi.org/10.1037/h0037039

Tajfel, H., \& Turner, J. C. (1986). The social identity theory of intergroup behaviour. In S. Worchel \& W. G. Austin (Eds.), Psychology of intergroup relations (pp. 7-24). Chicago, IL: Nelson-Hall.

\section{Copyrights}

Copyright for this article is retained by the author(s), with first publication rights granted to the journal.

This is an open-access article distributed under the terms and conditions of the Creative Commons Attribution license (http://creativecommons.org/licenses/by/3.0/). 